How to label bruxism that is a sign of a disorder? That's the question! Response to letter by Meira e Cruz \& Ettlin (2018)

\title{
Lobbezoo, Frank
}

2018-12

Lobbezoo , F , Ahlberg , J \& Manfredini , D 2018 , ' How to label bruxism that is a sign of a disorder? That's the question! Response to letter by Meira e Cruz \& Ettlin (2018) ' , Journal of Oral Rehabilitation, vol. 45 , no. 12 , pp. 922-923 . https://doi.org/10.1111/joor.12717

http://hdl.handle.net/10138/306639

https://doi.org/10.1111/joor.12717

publishedVersion

Downloaded from Helda, University of Helsinki institutional repository.

This is an electronic reprint of the original article.

This reprint may differ from the original in pagination and typographic detail.

Please cite the original version. 


\title{
How to label bruxism that is a sign of a disorder? That's the question! Response to letter by Meira e Cruz \& Ettlin (2018)
}

\author{
Frank Lobbezoo $^{1}$ (D) | Jari Ahlberg ${ }^{2}$ (D) | Daniele Manfredini ${ }^{3}$ (D)
}

\author{
${ }^{1}$ Department of Oral Kinesiology, Academic Centre for Dentistry Amsterdam (ACTA), University of Amsterdam and Vrije Universiteit Amsterdam, Amsterdam, \\ The Netherlands \\ ${ }^{2}$ Department of Oral and Maxillofacial Diseases, University of Helsinki, Helsinki, Finland \\ ${ }^{3}$ School of Dentistry, University of Siena, Siena, Italy \\ Correspondence \\ Frank Lobbezoo, Department of Oral Kinesiology, Academic Centre for Dentistry Amsterdam (ACTA), University of Amsterdam and Vrije Universiteit \\ Amsterdam, Amsterdam, The Netherlands. \\ Email: f.lobbezoo@acta.nl
}

\section{Dear Editor,}

First of all, we would like to thank Dr. Meira e Cruz and Dr. Ettlin for their Letter to the Editor of the Journal of Oral Rehabilitation, ${ }^{1}$ in which they advocate a more comprehensive classification system that includes not only primary bruxism but also secondary bruxism. Their proposal is a reaction on the recent international consensus paper by Lobbezoo et $\mathrm{al}^{2}{ }^{2}$ in which separate definitions for sleep and awake bruxism are described, along with an update of the grading system that Lobbezoo et al $^{3}$ proposed in 2013 to determine the likelihood that a certain assessment of bruxism actually yields a valid outcome. Further, Lobbezoo et $\mathrm{al}^{2}$ proposed a classification for bruxism based on its possible clinical consequences (viz., harmless behaviour, risk factor or protective factor). Clearly, Meira e Cruz \& Ettlin appreciated this classification, because they label its underlying principle (i.e, that bruxism is no longer considered as a disorder or disease) as "most important(ly)." So far, everyone is aligned nicely. However, we do not understand the paragraphs that follow in Meira e Cruz' \& Ettlin's Letter. ${ }^{1}$ Contrary to what Meira e Cruz \& Ettlin imply, we are very much aware of the fact that bruxism can also be attributable to identifiable aetiologies, as evidenced by many of our own review articles and research papers. ${ }^{4-11}$ Specifically for that reason, both newly proposed definitions for sleep and awake bruxism end with the phrase "in otherwise healthy individuals," ${ }^{2}$ indicating that bruxism can indeed be a sign of a disorder in some individuals. This phrase refers to the term "secondary bruxism" that is advocated by Meira e Cruz \& Ettlin. Lobbezoo et al $^{2}$ state that "from a nosological point of view, the adoption of different names for bruxism being or not being a sign of a disorder may be considered." As per Meira e Cruz' \& Ettlin's suggestion, labelling bruxism as primary or secondary could be one of the options. However, it should be pointed out that in the near future, knowledge on the physiopathology of both sleep bruxism and awake bruxism is expected to increase, thereby yielding a reduction of bruxism activity of unknown aetiology and thus rendering the debate on primary bruxism vs secondary bruxism increasingly sterile. Nevertheless, we are open for other suggestions, both for alternative names and for alternative classifications. As the title of the 2018 international consensus paper clearly states: the work is still under construction!

\section{ORCID}

Frank Lobbezoo (iD http://orcid.org/0000-0001-9877-7640

Jari Ahlberg iD http://orcid.org/0000-0002-6052-0441

Daniele Manfredini iD http://orcid.org/0000-0002-4352-3085

\section{REFERENCES}

1. Meira e Cruz M, Ettlin D. Bruxism - What's missing in the new consensus definition? Letter to the Editor. J Oral Rehabil. 2018;45:921.

2. Lobbezoo F, Ahlberg J, Raphael KG, et al. International consensus on the assessment of bruxism: report of a work in progress. J Oral Rehabil. 2018;45:837-844.

3. Lobbezoo F, Ahlberg J, Glaros AG, et al. Bruxism defined and graded: an international consensus. J Oral Rehabil. 2013;40:2-4.

4. Lobbezoo F, Naeije M. Bruxism is mainly regulated centrally, not peripherally. J Oral Rehabil. 2001;28:1085-1091.

5. Lobbezoo F, van Denderen RJA, Verheij JGC, Naeije M. Reports of SSRI-associated bruxism in the family physician's office. J Orofacial Pain. 2001;15:340-346.

6. Lobbezoo F, van der Zaag J, Naeije M. Bruxism: its multiple causes and its effects on dental implants. An updated review.. J Oral Rehabil. 2006;33:293-300.

7. Lobbezoo F. Taking up challenges at the interface of wear and tear. J Dent Res. 2007;86:101-103.

8. Rintakoski K, Ahlberg J, Hublin C, et al. Bruxism is associated with nicotine dependence: a nationwide Finnish twin cohort study. Nicotine Tob Res. 2010;12:1254-1260. 
9. de Knegt N, Pieper M, Lobbezoo F, et al. Behavioral pain indicators in people with intellectual disabilities: a systematic review. J Pain. 2013;14:885-896.

10. Lobbezoo F, Delwel S, Weijenberg RAF, Scherder EJA. Orofacial pain and mastication in dementia. Curr Alzheimer Res. 2017;14:506-511.
11. Verhoeff MC, Lobbezoo F, Wetselaar P, Aarab G, Koutris M. Parkinson disease, temporomandibular disorders, and bruxism: a pilot study. J Oral Rehabil. 2018;45:854-863. 